\title{
La existencia de Heidegger y el mar de Antonio Machado
}

\author{
The existence of Heidegger \\ and the Sea of Antonio Machado
}

\author{
Juan Merchán Alcalá \\ IES La Puebla de Vícar (Almería)
}

\section{RESUMEN}

El artículo pretende desentrañar el significado de uno de los símbolos de Antonio Machado, el del mar. Se han delimitado primero los significados más evidentes del símbolo para después abordar el análisis de las apariciones de la palabra en las que el significado presenta más dificultades. Se llega a la conclusión de que el valor central de la palabra es el de existencia.

Palabras Clave: desentrañar, significado, símbolo, mar, Heidegger, valor, existencia.

\begin{abstract}
The article seeks to unravel the meaning of one of the symbols of Antonio Machado, the sea. Firstly, the most obvious meanings of the symbol have been identified in order to later analyze the word's occurrence, where the meaning is more difficult to discern. The conclusion reached is that the central value of the word is existence.
\end{abstract}

Key words: Unravel, Meaning, Symbol, Sea, Heidegger,Value, Existence.

En la primera sección de las Poesías completas de Antonio Machado, la de Soledades, se encuentre el lector con un extraño poema, esta «Glosa» dedicada a los célebres versos de Jorge Manrique:

Nuestras vidas son los ríos

que van a dar en la mar,

que es el morir. ¡Gran cantar!

Entre los poetas míos

tiene Manrique un altar.

Dulce gozo del vivir:

mala ciencia del pasar,

ciego huir a la mar.

Tras el pavor de morir 


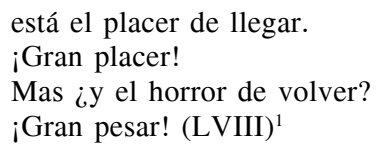

Su sorpresa resulta inevitable: ¿por qué el pasar es una mala ciencia?, ¿por qué «huir» y no, por ejemplo, ir, como parecería más lógico?, ¿adónde se llega tras el pavor de morir?, ¿adónde y por qué se vuelve?, ¿por qué es el volver un pesar?

Las Coplas de Manrique se encuentran situadas dentro de la tradición católica; la primera intención que le asalta, pues, es la de explicar el poema a partir de ella; pero los dos últimos versos la excluyen de modo tajante: en la escatología del catolicismo no existe ninguna vuelta atrás; el hombre muere; si ha sido bueno en esta vida, resucitará para la otra feliz; si ha sido malo, se condenará en el infierno para siempre; pero no habrá nunca un regreso horroroso a la vida anterior. Otra interpretación posible pudiera basarse en la doctrina órfico-pitagórica de la transmigración de las almas; pero el pitagorismo no considera un «gozo» el vivir; para esa escuela de pensamiento el vivir material es, en realidad, una muerte auténtica, la más verdadera; no se puede considerar, en ese caso, un «pavor» el morir: la muerte no constituye un pavor sino una bendición; y si el ciclo de las rencarnaciones es inevitable, tampoco tendría por qué resultar un «horror» el volver: cada vuelta cumplida supone un paso más hacia la perfección. Desechadas, pues, esas dos claves interpretativas, la mirada ha de dirigirse inevitablemente a la teoría nietzscheana del eterno retorno; pero en ella no existe vida inadecuada o visión inadecuada de la vida; eso sólo tiene sentido en una concepción de la existencia, como la cristiana, en la que hay un final, un llegar, con un premio o un castigo; en la filosofía de Nietzsche no existe ninguna moral de ese tipo ni un llegar definitivo, puesto que el devenir, con el eterno retorno, no tiene final. ¿Y cómo explicar ese «ciego huir a la mar» dentro de la teoría de Nietzsche? ¿Adónde huye el hombre y por qué? Además, debemos tener en cuenta que en la «Glosa» se está empleando un tono aseverativo que no admite duda alguna; si fuera la teoría del eterno retorno la que se encontrara en su base significativa, aparecería entonces esa doctrina como una verdad indiscutible, y Machado no sólo la cuestionó en el poema VI («Tarde») $)^{2}$, sino que al final de su vida la consideraba, junto con otras de Nietzsche, como la del superhombre, «cosas... improbables» (Machado, 1988: 2109).

\footnotetext{
${ }^{1}$ Como es ya habitual en los estudios sobre Antonio Machado, citamos sus poemas con los números romanos que aparecen en sus ediciones de Poesías Completas. Hemos utilizado la de Oreste Macrí (Machado, 1988). La «Glosa» concretamente cerraba la cuarta y última sección del libro Soledades en 1903. En 1907 formó parte de la tercera sección de Soledades. Galerías. Otros poemas. En las Poesías completas de 1917 tenía el número LVIII y estaba incluido en la sección «Humorismos, fantasías, apuntes. Los grandes inventos» de la parte de Soledades.

${ }^{2}$ Véase Merchán (2010).
} 
Y si para interpretar el poema no nos pueden servir ni la doctrina católica, ni los postulados pitagóricos sobre la transmigración de las almas ni la teoría del eterno retorno de Nietzsche, ¿adónde podemos acudir?, ¿qué camino tomar? Ante la duda, lo mejor es dirigir la mirada hacia la palabra central del poema para ver si en ella podemos hallar la buena dirección: el mar.

Los comentaristas de Machado, a lo largo de los años, han defendido opiniones diversas, y a veces contrarias, sobre la cuestión de cuál pudiera ser el significado, o los significados, que ese símbolo encierra. Pero se muestran todos ellos de acuerdo en una cuestión: se trata sin duda de una palabra compleja y difícil de interpretar ${ }^{3}$.

Advertidos pues suficientemente de las dificultades con las que nos vamos a encontrar, creemos que el procedimiento más adecuado para abordar el análisis es el de observar primero con cuidado qué valores claros — por lo menos en apariencia- presenta la palabra en poemas concretos de diferentes etapas del poeta. Miraremos, pues, el símbolo con ojos inocentes, como los del lector que se acerca por primera vez a la poesía de Machado. Esa observación nos permitirá ver cómo hay algunos grupos de poemas en el interior de los cuales el símbolo presenta un significado parecido o idéntico. Esas coincidencias nos servirán de base para elevarnos a interpretaciones menos evidentes.

Hasta 1903, año de la publicación del libro Soledades, incluyendo los ejemplos que en ese libro aparecen, además de en la «Glosa» encontramos la palabra «mar» utilizada en cuatro ocasiones, dos de ellas en su forma plural, «mares»: se trata de los dos extraños mares que llenan los dos paisajes, uno triste y otro alegre, de S. IV («El mar triste») y XLIV («La mar alegre») y que, dado el ambiente filosófico vitalista que rodea a Machado en esos momentos, se deben referir respectivamente a la visión pesimista que de la vida tenía Schopenhauer y a la optimista de Nietzsche. En el poema S. XII ${ }^{4}$, titulado Nevermore, se nos muestra la virgen, amarga pero necesaria para su labor creadora; a su música la llama «Salmodias de Abril», y surge cuando se han acallado en el interior del poeta las voces de «cien mares» («Salmodias de Abril, música breve, / sibilación escrita / en el silencio de cien mares, leve / aura de ayer que túnicas agita»). Las «Salmodias de Abril» se convierten en XXIII en «el salmo verdadero» que brota del corazón del poeta, precisamente cuando se dan las mismas circunstancias que en el poema anterior, es decir, cuando sus «viejos mares duermen» («El salmo verdadero / de tenue voz hoy torna al corazón, y al labio, / la palabra quebrada y temblorosa. / Mis

${ }^{3}$ Todas las monografías sobre Antonio Machado han dedicado algunas páginas al símbolo del mar. Lo estudian con exclusividad Gener (1966) y Ángeles (1966).

${ }^{4}$ Oreste Macrí, en la sección «Poesías sueltas», clasifica con números romanos, precedidos de S, los poemas que Machado no incluyó en las ediciones de Poesías completas (Machado, 1988: 739-836). «Nevermore» se publicó primero en la revista Electra en 1901; pasó luego al libro Soledades en 1903 pero Machado no lo incluyó en las ediciones de sus Poesías completas. 
viejos mares duermen, se apagaron / sus espumas sonoras / sobre la playa estéril. La tormenta / camina lejos en la nube torva»). En estos dos últimos casos, con la palabra utilizada también en plural, parece aludir el mar a algún obstáculo, sea interior o exterior, que dificulta o impide el proceso de creación artística.

Entre 1903 y 1907, año en que vio la luz su segundo libro, Soledades. Galerías. Otros poemas, vemos la palabra en cinco poemas. En dos de ellos se muestra ya sin lugar a dudas uno de sus significados más importante, el de muerte física, ese lugar ignoto adonde van a parar las vidas humanas. En XIII el poeta pasea al atardecer por las afueras de su ciudad y al pasar por un puente las aguas del río le hacen meditar sobre su propia vida: «Donde acaba el pobre río la inmensa mar nos espera». En XVIII la imagen de la barca se ha sustituido por una rama caída en el agua: «[...] Él piensa / que ha de caer como rama que sobre las aguas flota / antes de perderse, gota / de mar, en la mar inmensa». También parece guardar relación con la muerte el mar de XL: los ojos de la hermana morena, que representan, por una parte, el amor pasional, y por otra, la muerte siempre a ese amor asociada, le recuerdan al poeta las «noches de verano, / negras noches sin luna, / orilla al mar salado». En los dos casos restantes, I («El viajero») y II («He andado muchos caminos») la palabra presenta su significado directo, es decir, el de una gran extensión de agua salada.

De todos los poemas que Machado publicó en revistas y en la primera edición del libro Campos de Castilla, entre 1907 y 1912, siete de ellos tenían la palabra mar dentro de su composición. En cinco (XCVII, XCVIII, XCIX, CXIV y CLI), los que podemos considerar poemas en sentido estricto, la palabra muestra otra vez su significado directo. Las otras dos composiciones de esta etapa en las que la palabra aparece no son poemas propiamente dichos sino proverbios, en los que de forma rimada, como en el flamenco, se condensa un pensamiento a veces de largo alcance. Machado, nacido en una familia amante del folclore y admirador él mismo de las canciones populares, les concedió siempre una gran importancia. Estos concretamente pertenecen a los Proverbios y cantares (CXXXVI-II) que Machado incluyó en la primera edición de Campos de Castilla, de 1912. En ellos sí encierra la palabra mar un valor simbólico. Dice el número II que en realidad sólo camina aquel hombre que, como Jesús, anda por encima de las aguas del mar; los demás itinerarios posibles son sólo «surcos del azar». Podemos suponer que Jesús es más que hombre, es también Dios, y se diferencia de la mayoría de los hombres porque anduvo por encima del mar, es decir, se impuso al mar, lo dominó, lo venció. Los «surcos del azar» parecen aludir a pasos incontrolados sobre la tierra, sin dirección fija. Puede ocurrir que se refiera Machado a que unos hombres caminan y otros, en cambio, sólo se dejan ir, o bien a que sea el mismo poeta el que unas veces lleve un camino y otras, no. Si se tratara del segundo caso, podríamos relacionar este mar, por encima del cual debe hacer un camino el poeta, con los obstáculos que debe salvar en su vida cotidiana, 
aquellos obstáculos que veíamos en S. XII y XXIII. Por su parte, el «arcano mar» y la «ignota mar» del cantar CXXXVI-XV («Cantad conmigo en coro: Saber nada sabemos, [...]») parecen aludir respectivamente al pasado y al futuro del hombre, en sentido general: «de arcano mar vinimos, a ignota mar iremos». Lo que se encuentra situado entre esos dos mares, el «enigma grave», podría ser el presente de la existencia.

La palabra se convierte en una de las más importantes del vocabulario simbólico de Machado entre los años 1912 y 1917, fecha de publicación de las primeras Poesías completas, sobre todo en los nuevos poemas añadidos a la sección de Campos de Castilla,. En ocasiones sigue presentando todavía su valor directo; ocurre así, por ejemplo, en CIII («Las encinas»), CXV («A un olmo seco») y CXLIII («Desde mi rincón»). En otras, sin embargo, alude claramente a la muerte. En CXXVIII Machado interpela al agua de la lluvia que en esos momentos cae y le señala como destino último el mismo que el de su propio tiempo personal («¿Oh, tú, que vas gota a gota, / fuente a fuente y río a río, / con este tiempo de hastío / corriendo a la mar remota, [...]»); al meditar sobre el concepto de libertad de Bergson, cuyo libro Datos inmediatos de la conciencia acaba de recibir, expresa de manera cruda su desesperanza ante el futuro: «[...] si vamos / a la mar, / lo mismo nos ha de dar». CXXXVI-XLV habla de dos formas diferentes de morir, y una de ellas consiste sin duda en la disolución física de la vida individual: «Morir... ¿Caer como gota / de mar en el mar inmenso?». El CXLIX, dedicado a Narciso Alonso Cortés, el tema es el paso del tiempo y los esfuerzos desesperados del poeta para oponerse a su empuje destructor; el alma del poeta vence al «ángel de la muerte y el agua del olvido», aunque, actuando debajo de ella, en la materia, el tiempo lo lleva hacia la mar, hacia la muerte. Pero en CXXXVI-XLV, además de una forma de morir, la física, se habla también de la posibilidad de otra muerte distinta, de carácter más bien espiritual; morir puede consistir, como se decía antes, en diluirse en el mar «O ser lo que nunca he sido: / uno sin sombra y sin sueño, / un solitario que avanza / sin camino y sin espejo». Esta otra forma de muerte, a partir de la cual el poeta perdería sus señas de identidad - la sombra, el sueño, el camino y el espejo- podemos relacionarla con la que aparece en el grupo de poemas en los que la palabra mar aludía a obstáculos que entorpecen el camino verdadero del poeta; si esos obstáculos se impusieran, se caería en una especie de muerte espiritual. Es el mismo significado que debe de encerrar el mar sobre el que anduvo en La saeta (CXXX) el Jesús opuesto al del madero y también la mar con la que se representa la España finisecular en CXLIV, que había sumido en su inercia de debilitamiento y zafiedad a los espíritus inquietos antes de que pudieran alterarla; Antonio Machado y sus compañeros de promoción fracasaron también en el intento: «Fue ayer; éramos casi adolescentes, era / con tiempo malo, encinta de lúgubres presagios, / cuando montar quisimos en pelo una quimera, / mientras la mar dormía ahíta de naufragios». 
Vuelven a repetirse, pues, en estos casos los valores más importantes de la palabra: significado directo, muerte u obstáculos. Sin embargo, en la mayoría de los poemas de este periodo, el mar no alude a ninguno de ellos, por lo menos en apariencia. El más conocido de todos es el CXIX, publicado por vez primera en las Poesías completas de 1917 pero quizá compuesto poco después de la muerte de Leonor. Son los momentos en los que Machado anduvo más cerca de la creencia en un Dios trascendente y personal cercano al de Unamuno: «Señor, ya me arrancaste lo que yo más quería. / Oye otra vez, Dios mío, mi corazón clamar. / Tu voluntad se hizo, Señor, contra la mía. / Señor, ya estamos solos mi corazón y el mar». No parece que aquí el mar simbolice la muerte ni los obstáculos a los que hemos aludido. Otro poema, S. XXIV-I, enviado a Unamuno en una carta, no fue nunca incluido en libro alguno y parece un esbozo del anterior: «Señor, me cansa la vida, / tengo la garganta ronca / de gritar sobre los mares, / la voz de la mar me asorda. / Señor, me cansa la vida / y el universo me ahoga. / Señor, me dejaste solo, / solo, con el mar a solas». Tampoco da aquí la impresión de que con el mar Machado se esté refiriendo a la muerte o a esos obstáculos.

La cuestión se complica aún más en CXXXVII-V, cuando aparece la figura de un Dios que no siendo el mar se encuentra, sin embargo, en su interior («Dios no es el mar, está en el mar»); que creó el mar pero que nace del mar («Creó la mar, y nace / de la mar cual la nube y la tormenta»). Se trata de un mar con el que el hombre tiene que luchar cuando se encuentra despierto en CXXXVI-XXVIII (Todo hombre tiene dos / batallas que pelear: / en sueños lucha con Dios; y despierto, con el mar.»); que se hincha cuando

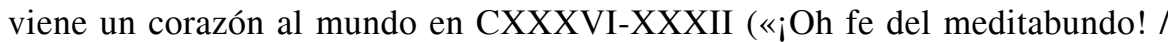
¡Oh fe después del pensar! / Sólo si viene un corazón al mundo / rebosa el vaso humano y se hincha el mar.»); sobre el que el hombre hace caminos en CXXXVI-XLIV («Todo pasa y todo queda, / pero lo nuestro es pasar, / pasar haciendo caminos, / caminos sobre la mar); junto al que hizo el marinero su jardín antes de la partida en CXXXVII-III («Érase de un marinero / que hizo un jardín junto al mar, / y se metió a jardinero. / Estaba el jardín en flor / y el marinero se fue / por esos mares de Dios») o un lugar misterioso de donde el ser humano tiene que extraer el conocimiento en CXXXVI-XXXV («Hay dos modos de conciencia»), en CXXXVII-II («Sobre la limpia arena, en el tartesio llano»), en CXXXVII-VIII («Cabeza meditadora»), en S. XXXVII-IV («Pensar el mundo es como hacerlo nuevo») y en S. LIX [3] («Mar»)

En los poemas publicados entre 1917 y 1924, año de Nuevas canciones, el mar vuelve a mostrar en ocasiones su valor directo como ocurre en CLVIII-V («Soria de montes azules»). En otros casos simboliza la muerte, o el olvido, que es una forma de muerte, como en CLXIV-[XV]-III («Las ascuas de un crepúsculo, señora»), pero también los obstáculos con los que se enfrenta el poeta en CLIX-I ( «Junto a la sierra florida»), o, incluso, ese lugar de donde debe sacar el hombre el conocimiento, como en CLXI-XCIII («¿Cuál es la verdad? ¿El río»). 
Sólo formaba parte de cinco poemas en los cancioneros apócrifos y en las «Canciones a Guiomar», En CLXXIII-III («Tu poeta»/ piensa en ti. La lejanía») no da la impresión de que se trate de un mar simbólico, aunque sea soñado. En CLXXIV-I («Asomado al malecón») el sueño aparece como una actividad rememoradora, un viaje al pasado; y ese ámbito temporal inconcreto queda simbolizado, otra vez, con la palabra mar. Tanto en el sueño como en la vigilia, está Guiomar presente, porque la amada, como siempre, es una creación del amante.

El mar de los poemas «Al gran Pleno o Conciencia integral» (CLXVIIXVI) y «Siesta» (CLXX) hemos de ponerlo en relación con el que antes simbolizaba ese lugar extraño del que surge la conciencia; y el de las «Últimas lamentaciones de Abel Martín» (CLXIX), con el pasado y el olvido.

En las «Poesías de la Guerra» aparece en doce ocasiones; y en ellas casi siempre se alude a un mar concreto, el de Valencia, la provincia que acogió a Machado de camino hacia el exilio (S. LXIV) o a los dos mares de España ((S. LXIII-VII). Sin embargo, en uno de estos poemas finales, S. LXIII-III, titulado «Amanecer en Valencia (Desde una torre)», es el olvido, de nuevo, el significado que se impone. Desde 1917 el olvido ha ido adquiriendo una importancia cada vez mayor entre los diferentes matices significativos que la palabra ha acumulado con el paso del tiempo.

Y hemos dejamos para el final el caso más interesante y clarificador, a nuestro entender, de aparición de la palabra en la obra de Machado. Se trata de «Poema de un día» (CXXXVIII), fechado en Baeza en 1913. Realiza en él Machado una transcripción poética, marcada por el tic-tac del reloj, del transcurrir monótono de un día cualquiera de su vida en esa población. Habla mentalmente con Unamuno de la recepción de un libro nuevo, los Datos inmediatos de la conciencia, de Bergson, y, al referirse a la libertad de que dota el filósofo francés al hombre, relativiza su importancia, anteponiéndole la muerte como asunto principal. Para la muerte utiliza de modo inequívoco la palabra mar: «Algo importa / que en la vida mala y corta / que llevamos / libres o siervos seamos; / mas, si vamos a la mar /lo mismo nos ha de dar». Poco antes, se ha dirigido a Unamuno para decirle que su filosofía, que es también la de Machado, no es la misma que la de Bergson, y la describe de esta manera: "Agua de buen manantial, / siempre viva, / fugitiva; / poesía, cosa cordial. / ¿Constructora? / —No hay cimiento / ni en el alma ni en el viento-_. / Bogadora, / marinera, / hacia la mar sin ribera $»^{5}$.

Desde el significado de «muerte», por ejemplo, hasta el de «lugar por donde el hombre camina» hay una distancia grande, y no es de extrañar que todos los comentaristas de Machado hayan pensado que el poeta se ha servi-

\footnotetext{
${ }^{5}$ En los últimos años, dos tesis doctorales sobre Antonio Machado han dedicado parte de su contenido a indagar sobre las relaciones entre la filosofía de Bergson y la obra de Machado: véanse Merchán (2004: 11-186) y García Castro (2012: 343-359).
} 
do de la misma palabra para aludir con ella a aspectos diferentes de la realidad, según sus necesidades expresivas o según la etapa de su vida en la que se encuentre. Como resumen de la opinión general podemos citar las palabras con las que Rafael Lapesa termina el análisis que le dedicó: «Su polisemia trasluce los cambios que el pensar y el sentir de Machado experimenta a lo largo de su vida» (1989: 77).

Llegaríamos así a una conclusión que contradiría en lo profundo la impresión que el lector de Machado recibe al terminar la lectura de sus poemas, la de que Machado con todos sus símbolos siguió un mismo procedimiento: se elevó desde una realidad puramente física hasta una realidad espiritual, siempre la misma, aunque con la posibilidad de adquirir matices diferentes: la fuente es la vida, el mármol la eternidad, el jardín la conciencia intuitiva, la sombra la muerte creadora, la sed el deseo, el camino la vida del poeta, etcétera. ¿No ocurre lo mismo con el símbolo del mar? ¿No existe un significado general de la palabra que pueda acoger dentro de sí todos esos significados parciales que le hemos descubierto? En apariencia, no; pero si partimos de lo que Machado ha dicho de la filosofía de Unamuno y nos situamos en la dirección que marca el pensar de Martin Heidegger, veremos que, como los demás, el símbolo del mar encierra también un significado general, uno solo.

Dice Machado en «Poema de un día» que la filosofía de Unamuno se dirige «hacia la mar sin ribera», o sea, que esa filosofía tiene su interés puesto en un mar ilimitado en el que el hombre no encuentra asideros para descansar. Para Machado lo importante es ese acercamiento de Unamuno a la vida. Como la vida es cambio continuo, algo inaprensible, la filosofía de Unamuno no es sistemática, como la de Bergson, sino extemporánea, «diletantesca, / voltaria y funambulesca»; como se ocupa de la vida, ha de estar «siempre viva»; no estática, fijada en conceptos, sino «fugitiva». Pero Machado no tiene centrada su atención en la vida general, como Unamuno, sino en su vida de hombre individual. La «mar sin ribera» hacia la que Machado supone que Unamuno encamina su filosofía, esa alma que no tiene «cimientos» y que no puede explicarse, por tanto, con una teoría «constructora», sistemática, esa alma es la existencia humana, y a ella alude Machado con el símbolo del mar. El valor simbólico de la palabra mar en su poesía es siempre, en todos los casos y en todas las épocas, el existir humano, pero, eso sí, entendiendo la existencia de una determinada manera. Para la lengua común y para la filosofía algo «existe» cuando tiene una presencia, cuando tiene, como diría Heidegger, un «ser ante los ojos», cuando es un objeto para el sujeto. Heidegger, sin embargo, nada más comenzar la andadura de El ser y el tiempo, insiste una y otra vez en que a la existencia del Dasein —José Gaos tradujo la palabra alemana por «ser ahí»-, es decir, del ente que va a analizar en busca del ser, el que sabe de la verdad, le conviene el sentido etimológico de «estar fuera», de «ser relativamente a», no el de «presencia»: 
La «esencia» de este ente está en su «ser relativamente a». El «qué es» (essentia) de este ente, hasta donde puede hablarse de él, tiene que concebirse partiendo de su ser (existentia). El problema ontológico es justamente el de mostrar que si elegimos el término de existencia para designar el ser de este ente, este término no tiene ni puede tener la significación ontológica del término tradicional existentia: existentia quiere decir ontológicamente «ser ante los ojos», una forma de ser que por esencia no conviene al ente del carácter del «ser ahí» (1989:54).

El Dasein, el «ser ahí», el ente que abre el mundo, no tiene un ser estable como los demás entes de su alrededor, a los que él ilumina. Dice Heidegger: «hasta donde puede hablarse de él [de un posible ser de este ente]». Con esa salvedad se refiere a que en realidad el Dasein no tiene un «ser» sino un «poder ser», una posibilidad. Quizá lo más terrible del hombre, más aún que el dolor, la muerte o la ceguera en que vive, es eso tan simple: el existir humano es un estar «lanzado» ya de modo irrevocable y para siempre, sin haberlo pedido, a recorrer un camino, sin posibilidad alguna de frenar y detenerse, sin asideros, un «mar sin riberas» en las que poder anclar. Lanzado y proyectado sobre las posibilidades que le hacen frente. «Ser relativamente a» quiere decir que su ser, su verdad, no está en el «ahí» fáctico del que parte sino en la proyección concreta que ha elegido; dice Heidegger: «su estado de yecto' es la forma de ser de un ente que es en cada caso sus posibilidades mismas, de tal suerte que se comprende en ellas y por ellas (se proyecta sobre ellas)» (1989: 201). El Dasein tiene el ser en la posibilidad elegida, y en términos generales hay dos posibilidades: la de una existencia auténtica y la de una existencia inauténtica. Puede estar proyectado sobre su propia muerte, la que lo ha llamado desde el estado afectivo especial de la angustia, tener su ser en la muerte propia, «ser» «ya» esa muerte. En tal caso estará en la verdad, porque la muerte es su posibilidad más cierta, será libre para la muerte y podrá organizar su vida atendiendo al hecho de que las demás posibilidades de la vida son sólo eso: posibilidades de importancia secundaria. La existencia humana, ese «ser relativamente a», puede ser un «ser relativamente a... la muerte». En ese caso, se puede decir, en efecto, que el mar (la existencia) es, en efecto, la muerte.

1. El mar De MACHAdo, Símbolo DEl EXISTIR hUMANO EN CUANTO PROYECCIÓN SOBRE LA MUERTE PROPIA.

Antes que a cualquier otra realidad simbólica añadida, la palabra mar alude, como es lógico, a una realidad física, y ése es el valor que presenta la palabra en muchos poemas de Machado. Ésa es la base real, concreta, en la que se apoya el valor simbólico posterior. Y la relación que se establece en su poesía entre realidad física y valor simbólico nunca es caprichosa, como ocurriría más tarde con los poetas surrealistas. Frente al río, que tiene sus 
cauces y sus límites, el mar se muestra al hombre como lo sin cauce y lo ilimitado. Si la vida humana se parece al río, un camino mensurable, allí donde vaya a parar se parecerá al mar, a lo inmenso. Y la grandiosidad es precisamente una de las notas características del mar dentro de la simbología tradicional. Dice J-E Cirlot en su diccionario de símbolos que «En el océano, la movilidad perpetua y el carácter informe de las aguas son los dos aspectos esenciales, aparte de la grandiosidad» (1994: 337).

Simboliza la muerte el mar de Machado, sin duda, en algunos casos de $S G O P$, como XIII («Donde acaba el pobre río la inmensa mar nos espera»), XVIII («antes de perderse, gota / de mar, en la mar inmensa») y XL («negras noches sin luna / orilla al mar salado»); de Campos de Castilla, como CXXVIII («mas, si vamos / a la mar, / lo mismo nos ha de dar»), CXXXVIXV («De arcano mar vinimos, a ignota mar iremos»), CXXXVI-XLV («Morir... ¿Caer como gota / de mar en el mar inmenso») y CXLIX («sus aguas cenagosas huyendo hacia los mares»); y de Nuevas canciones, como CLXILXXXVII («como yo, cerca del mar, / río de barro salobre, / ¿sueñas con tu manantial?»), CLXIV-XIII-VI («mas no tiene prisa / por ir a la mar»), CLXIVXV-III («yo voy hacia la mar, hacia el olvido») y CLXV-III («Pero aunque fluya hacia la mar ignota»).

En esos ejemplos, como todos los críticos señalaron en su día, el mar simboliza, en efecto, la muerte; pero sólo si entendemos por muerte no un suceso físico ya ocurrido sino una posibilidad del existir humano, la más propia y auténtica. Habla otra vez Heidegger: «La muerte es posibilidad de ser que ha de tomar sobre sí en cada caso el «ser ahí» mismo. Con la muerte es inminente para el «ser ahí» él mismo en su «poder ser» más peculiar» (1989: 273). Y es que el hombre sólo puede tomar la muerte en dos sentidos: o bien, se trata de la muerte de los otros, en cuyo caso se está hablando de una muerte objetivada, un concepto, un «ser ante los ojos», estable y definido como el de los demás entes de alrededor, y dominable como ellos, o bien se trata de su propia muerte, en cuyo caso se está hablando de una de sus posibilidades de ser, siempre posibilidad, nunca realidad.

En un poema de 1906 se pregunta Machado: «¿Qué es esta gota en el viento / que grita al mar: soy el mar?» (XIII). Esa afirmación tajante: «soy el mar» se ha querido entender como una manifestación de fe panteísta por parte de Machado. Y tiene su justificación, porque en el simbolismo tradicional «frente a la gota, el océano es un símbolo de la vida universal» (Cirlot, 1994: 337). Sin embargo, lo que debemos entender es lo que se dice de modo explícito: yo soy ahora ya el mar; es decir, en su proyección sobre su posibilidad más cierta, el Dasein «puede ser» ya su muerte propia. Pero, además de ésa, tiene otras posibilidades. 


\section{El MAR DE MACHADO, SÍMBOLO DEL EXISTIR HUMANO EN CUANTO PRO- YECCIÓN SOBRE LA MUERTE DE LA COTIDIANEIDAD}

El ser del existir humano — si alguno tiene- no es un ser estático, fijo e intemporal, analizable racionalmente como el ser de los objetos de las ciencias, y no posee por lo tanto una sustancia que le sirva de fundamento. Su ser consiste en estar proyectado siempre sobre las posibilidades que le hacen frente. Puede estar proyectado de modo propio y auténtico sobre su posibilidad más peculiar, la de su propia muerte; pero por lo común está proyectado sobre las múltiples posibilidades secundarias derivadas de los mil avatares cotidianos, y tiene su ser en ellas. El Dasein «es» generalmente ese término medio de la cotidianeidad, ese mundo uniforme de lo que Heidegger llana «uno» en el que toda nota individual queda diluida. La naturaleza que ahí adquieren las relaciones personales hace que parta siempre de una interpretación de su realidad que no es de él sino de los demás, de todos. El «ser ahí" cotidiano — dice Heidegger - saca la interpretación pre-ontológica de su ser de la inmediata forma de ser del 'uno» (1989: 146); sus preocupaciones personales auténticas, sobre todo la más auténtica de todas, la de la muerte, se apartan, se falsean y se sustituyen por otras. «No es él mismo, los otros le han arrebatado el ser» (1989: 143).

A esta forma de ser inmediata del Dasein cotidiano la llama Heidegger «muerte» — «El 'ser ahí' muere fácticamente mientras existe, pero inmediata y regularmente en el modo de la caída» (1989: 274) — siguiendo una larga tradición religiosa para la cual no vivir en la verdad es no vivir una vida auténtica, no vivir sino morir. Baste recordar que ya en la antigua Grecia para los seguidores de Orfeo «la existencia encarnada se parece más bien a una muerte, mientras que la muerte constituye el comienzo de la verdadera vida» (Eliade, 1979: 188). Nosotros, para seguir la tradición, también la llamaremos «muerte»: la otra muerte o la muerte espiritual.

Ésa, sin embargo, es sólo otra posibilidad del existir humano, la impropia. El «estar ya en la muerte», aquella posibilidad propia, la simbolizó Machado en su poesía con la palabra «mar». Nada tiene de extraño, pues, que esta otra posibilidad, la de «estar ya en la otra muerte» quede simbolizada también con la misma palabra. Hay que tener en cuenta, como ya se ha dicho, que, en sentido estricto, el mar no es un símbolo de la muerte física empíricamente constatable en el mundo de alrededor sino de la existencia humana.

La relación simbólica entre el mar y la muerte física alcanzaba su justificación en la semejanza entre río-vida por un lado y mar-muerte por otro, porque una de las características del mar en la simbología tradicional era la de lo grandioso, lo ilimitado. Pero otra era la «del carácter informe de las aguas» (Cirlot, 1994: 337). La perspicacia crítica de Geoffrey Ribbans lo llevó a considerar la posibilidad de que el mar no estuviera siempre relaciona- 
do en la poesía de Machado con la muerte física. En una nota explicativa, puesta precisamente al pie de la «Glosa» a Manrique en su edición de $S G O P$, cita un fragmento de un libro, Cantos populares españoles (1882), de F. Rodríguez Marín, amigo del padre del poeta, en el que se dice que el mar en el folclore significa «lo indistinto, la gran generalización» donde «se sepulta ad perpetuam todo lo determinado e individual» (Machado, 1984: 172).

En su propio ambiente familiar, pues, disponía ya Machado de los instrumentos teóricos adecuados para poder establecer de inmediato una identificación mar-muerte-otra muerte. Esa identificación se encontraba ya en el folclore popular, al estudio del cual tanto tiempo y amor dedicó su padre.

Ese significado de existencia humana como «otra muerte» fue el primero en aparecer. Los «cien mares» de «Nevermore» tenían que estar en «silencio» para que el poeta pudiera escribir sus «Salmodias de Abril». En XXIII los «viejos mares» del poeta tenían que dormir para que volviera «la paz al cielo» y pudiera aparecer entonces «en la bendita soledad, tu sombra». En una primera lectura, le asignamos a esos mares el significado impreciso de «obstáculos en la labor del poeta». Ahora podemos ya reconocer esos obstáculos. Para tener contacto con la verdad, el poeta ha de despertar del adormecimiento en el que habitualmente, como hombre, vive. O dicho de otro modo: la proyección que en la existencia inauténtica tiene el Dasein sobre posibilidades impropias y el olvido consiguiente de su posibilidad más propia lo sumen en una caída, en la pérdida del ser, en la ausencia de verdad; y ese estado de falsedad lo imposibilita para la escucha de la voz necesaria, la que habla en el silencio.

En «La saeta» $(\mathrm{CXXX})$ dice Machado que no quiere cantar al Cristo de la cruz sino al que anduvo en el mar, y en CXXXVI-II que no se deben llamar caminos a «los surcos del azar», que sólo camina de verdad el que «anda, como Jesús, sobre el mar». Así pues, existen dos formas de andar: la de Jesús y la de la mayoría de los hombres. Pero, ¿qué ve Machado en la figura de Jesús? El del Evangelio venció a la muerte física al resucitar al tercer día, y anduvo también en uno de sus milagros por encima del mar de Galilea. El recorrido que realizó por encima de las aguas no puede simbolizar la victoria sobre la muerte física puesto que aún no había muerto. Ese mar tiene que significar algo diferente a la de la muerte física, y ese Jesús tiene que ser otro diferente al de la versión oficial. Juan de Mairena, sin tacharla de falsa, admite la posibilidad de otra versión, la de «los herejes, coleccionistas de excomuniones». Jesús pudo ser, «como muchos piensan, el hijo de Dios, venido al mundo para expiar en la Cruz los pecados del hombre», o «el hijo del hombre que se hizo Dios para expiar en la Cruz los pecados de la divinidad» (Machado, 1989: 2388). Sabemos que ese pecado de la divinidad consistió en haber dado al hombre la nada-razón, como se dice en CLXX («Siesta»): «honremos al Señor, que hizo la Nada / y ha esculpido en la fe nuestra razón». Es verdad que el hombre con ese regalo divino pudo penetrar en la selva del 
mundo; mediante los principio lógicos, los conceptos y las ideas, mediante su poder anulador de las cualidades individualizadoras, de todo lo que se manifiesta al hombre en las intuiciones, consiguió detener el flujo incesante de la vida, y de su propio existir, consiguió la unidad de la multiplicidad abigarrada y caótica. El mundo es todo él «presencia», y la razón, con ese distanciamiento suyo respecto a lo real inmediato, nos salva del mundo («Él nos libra del mundo -omnipresencia-, [...]»). Al salvarlo de la presencia, el Dios-Razón regala al hombre a cambio el mundo de la distancia y de la ausencia ( $\ll \mathrm{Al}$ Dios de la distancia y de la ausencia»). La presencia inmediata del contenido de las intuiciones, algo individual y cambiante, la razón la convierte en lo genérico, en lo común a todos los hombres. Lo que aparece - el ser de la poesía- lo convierte en no-ser. Lo conceptualizado es ya la razón comunitaria, lo social, el uno, el «mar».

Jesús es un símbolo del hombre, que se ha hecho Dios - «el Ser que se es» (CLXVII [XV] - al crear la razón, esa nada que ha sido el ser de la metafísica occidental desde Platón hasta Hegel, un hombre que ha podido detener el mundo, vaciarlo con los conceptos e iniciar el camino del conocimiento («nos abre senda para caminar»). Se ha salvado del mundo, de lo que se hace presente de modo inmediato en la intuición, sobre todo de su propio tiempo y de su propia muerte. Y es ése precisamente el pecado que ha de purgar en la cruz: Dios, el hombre-Dios, tiene que sufrir en sus propias carnes lo terrible del existir humano, lo que su razón ha intentado ocultarle por todos los medios tras un velo de sombra; Juan de Mairena ponía en boca de Abel Martín las siguientes palabras: «Cierto, decía mi maestro, que si el Cristo no hubiera muerto entre nosotros, la divinidad no tendría la experiencia humana que se propuso realizar y sabría del hombre tan poco como los dioses paganos» (Machado, 1989: 2353).

Pero Jesús es también el poeta, el hombre capaz de sentir intuiciones profundas sobre lo que deviene, sobre su propio existir; mezcladas siempre, eso sí, con ese velo de sombras de la razón. Jesús es un símbolo del hombre, pero de esas dos formas de ser hombre, no sólo del que se oculta la verdad sino también del que anda por encima de las aguas del «mar» de lo cotidiano - y como parte importante de eso cotidiano, la España tradicional, castiza y dogmática a la que siempre atacó Machado-, de aquel cuyo camino no es un simple surco del azar. El ser del hombre es posibilidad, y entre sus posibilidades está la de permanecer siempre sumergido en el mar, pero también la de andar por encima de él. El hombre, como Jesús, puede resucitar y vencer a la muerte, a esa muerte. Entre el «del madero» y «el que anduvo en la mar» Machado prefiere cantar al segundo, el Jesús de la esperanza y, al mismo tiempo, el Jesús que duda en el Huerto de los Olivos.

Hay dos formas distintas de morir en el universo simbólico de Machado; el mismo poeta lo dejó bien claro en CXXXV-XLV: «Morir... ¿Caer como gota / de mar en el mar inmenso? / ¿O ser lo que nunca he sido: /uno, sin 
sombra y sin sueño, / un solitario que avanza / sin camino y $\sin$ espejo?» La sombra, el sueño, el camino y el espejo son símbolos fundamentales en la esencia de Machado como poeta. Ser sin esos atributos supondría no ser poeta, estar imposibilitado para el contacto con las sombras, encontrarse inmerso en el mar uniforme del uno.

El valor simbólico del mar como muerte cotidiana vuelve a hacer su aparición en «Una España joven» (CXLIV-1915). El mar cotidiano es ahora la sociedad española de principios del siglo XX, un monstruo que, del mismo modo que la muerte física devora insaciable las vidas de los hombres, había hecho naufragar a las mejores almas, las que habían intentado cambiar las cosas antes de que Machado y sus jóvenes compañeros de promoción literaria salieran a combatir.

Las abejas que elaboran la miel en CLIX-I, como en otros poemas que Machado escribiera en diferentes épocas, simbolizan el proceso de creación poética. En esa actividad la voz debe ser pura, no contaminada por los ecos del mar de la cotidianeidad. Ahora, sin embargo, la miel no es totalmente dulce: reconoce Machado que no está en su mejor momento poético: «Junto a la sierra florida, / bulle el ancho mar. / El panal de mis abejas / tiene granitos de sal».

Terrible es, pues, para el hombre estar proyectado sobre la posibilidad ineludible de su propia muerte. Terrible también estar proyectado sobre otras posibilidades que lo alejan de la verdad. Pero lo más terrible de todo, sin embargo, quizá sea el puro existir, el hecho de «estar lanzado».

\section{El mar de Machado, Símbolo DEl EXISTIR humano EN CUANTO «ES- TAR LANZADO»}

Si la referencia de la palabra a la muerte física tenía su justificación en la simbología tradicional ya que allí el mar es lo grandioso, lo ilimitado, y la referencia a la otra muerte también, porque en esa simbología el mar es lo informe, lo indistinto, la alusión al puro existir encuentra su fundamento en la tercera de las características, la que nos falta: la movilidad perpetua. En el diccionario de Cirlot se la citaba en primer lugar (1994: 337). Como el mar, la existencia humana también se encuentra siempre sometida a un movimiento continuo, o mejor, para no confundirnos con la traslación espacial, a un continuo cambio.

Si la esencia del existir humano está en la temporalidad, como mostró Heidegger, el puro existir es el tiempo vacío. El niño de «Recuerdo infantil», encerrado en el armario, detenido en su actividad constante, alejado de las preocupaciones cotidianas sobre las que proyecta su ser, siente el fluir desnudo del tiempo; él es el poeta puro: «El niño está en el cuarto oscuro, / donde su madre lo encerró; / es el poeta, el poeta puro / que canta: ¡el tiempo, el tiempo y yo!» (Machado, 1989: 1935). 
No hay razones suficientes para suponer que el mar que aparece en el poema CXIX («Señor, ya estamos solos mi corazón y el mar»), y en su esbozo, S. XXIV («Señor, me dejaste solo/ solo con el mar, a solas»), aluda a la muerte física. En una carta a Juan Ramón Jiménez, escrita poco después de morir Leonor, le dice: «Cuando perdí a mi mujer pensé pegarme un tiro» (2001: 326), pero es preciso tener en cuenta que CXIX apareció en 1917 y que, por lo tanto, debió de ser escrito bastante tiempo después de 1912; además, siempre que hasta entonces el mar había simbolizado la muerte física se había tratado de la muerte de todos los hombres, no la de Machado en particular. Lo más probable es que con el mar se refiera en estos poemas al hecho mismo de existir.

La existencia humana presenta, por encima de cualquier otra, esa característica clave de la movilidad, de la temporalidad. La meta que la razón humana persigue es la de detener el tiempo, echar el ancla en el mar de la existencia. El marinero del poema CXXXVII-III es un símbolo más del ser humano: «Érase de un marinero / que hizo un jardín junto al mar, / y se metió a jardinero. / Estaba el jardín en flor, / y el marinero se fue / por esos mares de Dios». Frente al jardín, un lugar estático, aparece aquí el mar, un lugar en continuo movimiento; frente a la actividad del jardinero, sedentaria, la del marinero, siempre nómada, nunca estable. El jardín se encuentra situado junto al mar, pero no se trata de un jardinero metido a marino sino de lo contrario. Lo que en realidad ocurre es que ambos personajes simbolizan al hombre, que unas veces realiza una actividad semejante a la del marino y otras a la del jardinero. Con las flores del jardín se refiere Machado a las obras del hombre, pero unas obras relacionadas con lo que a él le importa en esos momentos: la verdad, el conocimiento humano. Cuando el marinero (el hombre) se hace jardinero (el hombre), y con su actividad agrícola sedentaria (la actividad racional) ha conseguido que el jardín esté en flor, es decir, ha alcanzado los frutos que buscaba (los conceptos y las ideas), se da cuenta de que la verdad que a él le interesa, la relacionada con lo esencial humano, no está en esos productos de la razón, de que ha de sacarla del mar, es decir, de la propia existencia. Y tiene que volver a ser lo que ha sido siempre: marinero. De ahí partió la filosofía de Heidegger, y de ahí partieron las intuiciones poéticas de Machado. En busca de la misma meta imposible.

Otro proverbio, el CXXXVI-XLVII, dice así: «Cuatro cosas tiene el hombre / que no sirven en la mar: / ancla, gobernalle, remos / y miedo de naufragar». Con el ancla se refiere Machado a la razón: el pensamiento racional humano intenta siempre anclar en el mar de la existencia y detener el fluir constante del tiempo, proporcionar unos cimientos sólidos a un edificio que está sostenido sobre un abismo; una tarea imposible. Con el timón alude a la imposibilidad humana de dirigir, de gobernar de forma consistente la vida en un sentido concreto, porque la vida es algo imprevisible que puede en cualquier momento, si ella quiere, torcer cualquier camino previamente marcado 
por el hombre. Los remos son los apoyos o ayudas que el hombre pueda agenciarse en su intento de fundamentar y consolidar su andadura vital; algo en realidad poco útil en el siempre inestable mar de la existencia. Naufragar es, sin duda, morir; pero no se nos dice en el poema que el miedo a la muerte sea bueno o malo para el existir humano, o que sea inútil porque la muerte es inevitable, sino simplemente que el miedo no sirve para detener el «lanzamiento» y la «proyección» que la existencia es.

Muerte física, muerte espiritual, angustia de estar lanzado. Pero hay más: la ceguera en que el hombre vive.

\section{El MAR DE MACHADO, SÍMBOLO DEL EXISTIR HUMANO EN CUANTO «MUNDO»}

En un grupo de poemas que van desde 1915 a 1933 (S. XXXVI-1915, CXXXVI-XXXV- 1917, CXXXVII-II, 1917, CXXXVII-VIII, 1917, CLXIXCIII, 1923, CLXVII-VI, 1926, CLXX, 1933) aparece la palabra mar simbolizando una realidad imposible de conocer para el hombre. A esa realidad la llama el propio Machado «mundo» en S. XXXVII-IV («Medir las vivas aguas del mundo... ¡desvarío!») Y si el propio Machado lo dice no hay por qué contradecirlo. Pero, ¿de qué mundo se está hablando? Muy pocas palabras del idioma presentan un significado tan abierto como ésta. El mundo puede ser el universo, el todo; la naturaleza; la totalidad de los entes; un determinado ambiente o campo de estudios (el mundo de la moda, el mundo de las tortugas); mi mundo, es decir, la subjetividad. Todos estos «mundos» poseen una característica común: son «objetos» para el «ser ahí», su ser es un ser «ante los ojos» que no coincide con el ser del «ser ahí». El ser del «ser ahí» es existencia. Consiste en estar «lanzado» y «proyectado». Pero, ¿desde dónde? Desde un «mundo», el que él ha abierto, eso de que se preocupa, ese plexo de relaciones y de significados en el que el «ser ahí» se encuentra inmerso desde un principio, cuya verdad es su verdad, una comprensión previa de la cual tiene que partir necesariamente si quiere conocer, una pre-comprensión que tiende a explicarlo todo inmediatamente a partir del ser de los entes de alrededor y que intenta también explicar su propio ser a partir de esos mismos presupuestos. «Ahí», en el mundo, se encuentra la verdad, pero disfrazada, oculta. Como dice Heidegger, «[...] 'mundo' no significa en absoluto un ente ni un ámbito de lo ente, sino la apertura del ser» (2000: 68). El «ser ahí» tiene una intuición certera de la verdad, pero está oscurecida y anulada en la pre-comprensión dada ya de antemano por su mundo. Ese mundo es su «ahí», y de ahí proceden todas las dificultades para conocer la verdad. Resulta tan difícil de determinar que incluso Machado, que lo tenía en el centro de sus preocupaciones, unas veces lo llama «vida» y otras veces «mundo». Y no se trata sólo de un problema terminológico. Machado, situado en su momento histórico concreto, se deja llevar a veces por los conceptos y las palabras de 
Nietzsche e identifica esa realidad con la «vida», el caos originario, algo «ante los ojos», un presupuesto, fundamento, principio, sustancia, esencia, etcétera, de la misma naturaleza en el fondo que los de cualquier otra metafísica. No era posible para Machado — como tampoco lo era para Nietzsche_ pasar de la pura intuición y vislumbrar ese ámbito huidizo al que Heidegger, más tarde, intentó delimitar teóricamente, además de intuitivamente, en $\mathrm{El}$ ser y el tiempo.

Si el «mundo» del que estamos hablando es el «ahí» del «ser ahí», no se trata en ningún caso de algo independiente que esté situado fuera de él; es, por el contrario, como dice Heidegger, «una determinación existenciaria»: el «ser ahí» es de modo inmediato «mundo»: «El 'mundo' no es ontológicamente una determinación de aquellos entes que el 'ser ahí', por esencia, no es, sino un carácter del 'ser ahí' mismo» (1989: 77).

Si el existir humano, el «ser ahí», es de modo inmediato «mundo», y si el mar es símbolo de ese existir humano, nada hay de extraño en que Machado se refiera unas veces con el símbolo del mar a la muerte física como una posible proyección de la existencia, a la otra muerte como otra proyección posible, o al «mundo», un carácter de la existencia, una forma de ser previa a cualquier proyección posible. Tanto la muerte, como la otra muerte o el mundo son la existencia, el mar.

Las dos características principales de ese «ser en el mundo» se recogen en dos proverbios de Campos de Castilla, incluidos en las Poesías Completas de 1917: CXXXVI-XXIX («Caminante, son tus huellas») y CXXXVIXXIX ( «Todo pasa y todo queda»). Existe una diferencia esencial entre una «estela»y un «camino»: el camino es un trazado fijo y permanente, que descansa sobre un fundamento sólido, que tiene una consistencia, una estabilidad; la estela es sólo un trazo fugaz dibujado sobre el abismo, un camino sin suelo. El existir humano, el ser del «ser ahí», como la estela, no tiene fundamento alguno en que apoyarse, es un ser sin sustancia, un trazo escrito sobre el vacío, sobre la nada. Entre los afanes más persistentes del hombre ha estado siempre el intento infructuoso de averiguar la marca de su destino, la dirección que seguirá su vida. Pero no hay caminos prestablecidos por los que se pueda transitar seguro. El que el hombre va haciendo está marcado por las necesidades inmediatas que lo oscurecen, y no puede de ningún modo detenerlo, rectificarlo o volverlo a transitar ${ }^{6}$.

El mar de CXXXVI-XXXII («iOh fe del meditabundo! / ¡Oh fe después del pensar! / Sólo si viene un corazón al mundo / rebosa el vaso humano y se hincha el mar.») no parece que sea un universo abstracto que se hinche

\footnotetext{
${ }^{6}$ En sus Apuntes de filosofía Machado colocó «Todo pasa y todo queda» después de la siguiente cita de Bergson: «Nuestras necesidades son, pues, otros tantos rayos luminosos que dirigidos sobre la continuidad de las cualidades sensibles, dibujan cuerpos distintos» (Machado, 2007: 13).
} 
cuando el hombre alcanza una fe más allá de las fronteras de la racionalidad. El mar es el «mundo» medio de la cotidianeidad en el que el hombre está inmerso desde siempre, alejado de lo sagrado ${ }^{7}$. Que se hinche ese mundo cuando aparece un corazón quiere decir que se enriquece. $\mathrm{Si}$, como hemos hecho, en efecto, llamamos a ese mundo de la cotidianeidad «muerte», el corazón se levanta por encima de él, supera la muerte. Mas para que eso ocurra tiene que rebosar el vaso humano: tiene que salir el corazón de la muerte cotidiana y convertirse en algo más que lo humano común, en un hombre que, después del fracaso de la razón en la búsqueda de la verdad, sigue todavía, sin embargo, despierto, en vela, oyendo la palabra de Jesús: «¿Cuál fue, Jesús, tu palabra? / ¿Amor? ¿Perdón? ¿Caridad? / Todas tus palabras fueron / una palabra: velad» (CXXXVI-XXXIV).

El «mundo», pues, es existencia, y para conocerlo hay una dificultad evidente: el propio «ser ahí» que quiere conocer es también existencia, es decir, está dentro de lo que quiere conocer, y, allí dentro, él mismo participa del falseamiento, él mismo es en sí falsedad. Permaneciendo siempre dentro no lograría nunca el conocimiento fiable que pretende. No hay más remedio, pues, que salir fuera, situarse fuera de uno mismo, del «mundo», para intentar «ver». Pero desde fuera no hay otra forma de «ver» para el hombre que la razón, y la razón sólo puede actuar como sabe: convirtiendo lo fugaz, lo que se mueve (la existencia, el mundo, la vida) en algo eterno, estático, «ante los ojos»; analizando el ser del «ser ahí» como si de otro tipo de ser, el de las ciencias, se tratase. La razón, pues, falsea la realidad, pero otro camino, salvo que en esoterismos raros pensemos, no hay para el hombre. Su conocer es limitado, finito, frente al mar, lo ilimitado, lo infinito. Si quiere llegar hasta la verdad de sí mismo tiene que recurrir a la razón, tiene que ser un pescador que, sin dejar de serlo, se convierta en pez, o un pez que, sin dejar de serlo, se convierta en pescador: «Si quieres saber algo del mar, vuelve otra vez, / un poco pescador y un tanto pez» (S. XXXVII-IV). En CXXXVI-XXXV («Hay dos modos de conciencia») se expone el problema con todas sus consecuencias. Los peces que captura la razón humana, es decir, los conceptos, son peces muertos, realidades fijas y vacías, y los peces que persigue la otra conciencia, la intuitiva, peces vivos que no se pueden capturar. Pero ¿por qué las intuiciones poéticas no se pueden capturar? Porque están referidas a una realidad en continuo movimiento, la del existir humano. Por eso, irónicamente, Juan de Mairena quería construir una lógica no racional, en la que los silogismos presentaran como característica principal que sus premisas hubieran cambiado ya cuando se hubiera llegado a la conclusión, que también por ellas pasara el tiempo como por el hombre (Machado: 1989: 680-681). Y de ahí

\footnotetext{
${ }^{7}$ «Es el trajinar del hombre lo que lo aleja del misterio hacia la corriente, él va de una cosa habitual a una más próxima y pasa de largo junto al misterio, ese trajinar es el errar». Palabras de Heidegger citadas por Múgica (1995: 150).
} 
precisamente, de ese problema insoluble, es de donde partió Heidegger para su análisis: las intuiciones sobre la existencia que había tenido Kierkegaard, e incluso el hombre común, eran sólo eso: intuiciones; hacía falta construir un armazón teórico que prescindiera de los conceptos de la tradición metafísica occidental, que lograra fijar intelectualmente esas intuiciones y darles la solidez teórica necesaria. No es necesario insistir en las dificultades que encontró en su camino.

En CLXI-XCIII no se pregunta Machado por la conciencia sino por la verdad: «¿Cuál es la verdad? ¿El río / que fluye y pasa / donde el barco y el barquero / son también ondas del agua? / ¿O este soñar del marino / siempre con ribera y ancla?». Dicho de otro modo: ¿Es la verdad la vida, la existencia, a la cual la misma conciencia pertenece, y no puede, por lo tanto, dominarla desde fuera, o el soñar del marino, «siempre con ribera y ancla»? La ribera, como el ancla, es un símbolo que Machado suele utilizar para referirse al pensamiento humano, un pensar que tiene la intención de convertir en realidad estable y segura el movimiento incesante del mar de la vida. Ese pensamiento crea un mundo propio basado en los principios de la lógica, «los cuales, reducidos al principio de identidad que los resume y los reasume a todos, constituyen un solo y magnífico supuesto: el que afirma que todas las cosas, por el mero hecho de ser pensadas, permanecen inmutables, ancladas, por decirlo así, en el río de Heráclito»; pero cabe la posibilidad de que ese mundo, que Machado llama «apócrifo», «esté todo él cimentado sobre un supuesto que pudiera ser falso» (1989: 1998). De cualquier modo, lo más interesante de este poema es el uso de la palabra «soñar». Alude aquí a ese mundo apócrifo creado por la razón humana, cuando lo más normal es que se refiera en su poesía al conocer intuitivo. Debemos tener en cuenta para entenderlo que está colocada al lado de otra palabra con la que no concuerda, «marino». El marino es el existente, el que está en el mar, siempre en continuo movimiento. Si ese ente estuviera «despierto» desecharía por inútil el ser de la razón, quieto y eterno, que no le corresponde a su ser. Cuando no está despierto, cuando ha creado ese mundo de la razón, ajeno a su verdadero ser, es cuando «sueña». Podemos decir, pues, que el sueño, en general, no alude siempre en la poesía de Machado a la conciencia intuitiva, enfrentada a la racional; vemos aquí, por el contrario, que puede simbolizar precisamente esa conciencia racional. Porque el sueño es el conocer de la otra orilla: el pensar racional para el marino o el conocer intuitivo para el jardinero. El hombre es marino y jardinero al mismo tiempo: si intenta olvidarse de la razón para captar intuitivamente la existencia, sueña; cuando, como existente, crea un mundo lógico inmutable, también sueña.

En S. LIX [3], titulado significativamente «Mar», en S. XXXVII-IV («Pensar el mundo es como hacerlo nuevo») y también en CXXXVII-VIII («Cabeza meditadora»), una de las «Parábolas» de 1917, se exponen las limitaciones del pensamiento racional. Las ciencias sólo pueden actuar sobre los 
«objetos» de análisis que tienen un determinado ser, un ser «ante los ojos», y pueden estudiar al hombre de muchas maneras, cada una de las cuales tiene su nombre concreto - medicina, psicología, antropología, historia, etcétera- pero en ninguna de ellas el objeto de estudio es el hombre de verdad.

En otra de las «Parábolas» de 1917, la CXXXVII-II («Sobre la limpia arena, en el tartesio llano»), no es ya sólo la razón lo que se cuestiona; también la intuición. En la arena de la playa, frente al mar, hay dos hombres. Uno de ellos ha cerrado los ojos, ha borrado el mar de su pupila y, en sueños, se introduce bajo las olas, donde ve a Proteo, a las Nereidas y a Poseidón. El pensamiento del otro navega sobre las aguas o vuela por encima de ellas. La conclusión a la que llega este segundo personaje es la misma que ha dominado toda la filosofía occidental desde Platón: el mundo sensible es inestable, fugaz, perecedero; la verdad, no está en él, sino más arriba, en el mundo suprasensible de las ideas; la realidad inmediata del hombre, lo que en apariencia se muestra como más verdadero, la vida, es sólo una ilusión: Y piensa: «Es esta vida una ilusión marina / de un pescador que un día ya no puede pescar». El primero, en sueños, imaginando, ha logrado introducirse dentro del mar, de la existencia — de la vida, en la terminología de Machado-; allí, dentro de la corriente vital, sumergido en el «mundo», lo único que aparece como verdadero es lo vivo, lo vital; todo lo demás son sólo «ideas», por ejemplo la idea más ideas de todas: la muerte, algo de lo que nadie ha tenido jamás experiencia, que nadie ha visto, que está completamente fuera de lo real, de lo vital: «El soñador ha visto que el mar se le ilumina / y sueña que es la muerte una ilusión del mar».

El poema «Siesta» (CLXX) es una oración dirigida al Dios de la razón, al Dios de la nada, que aparece en medio de la existencia (el mar) para detenerla (echar el ancla) y crear un mundo nuevo, un mundo de silencio, distancia y ausencia, una sombra que no podrá llenar nunca el corazón del hombre: «Al Dios de la distancia y de la ausencia, / del áncora en el mar, la plena mar... / Él nos libra del mundo - omnipresencia-, / nos abre senda para caminar. / Con la copa de sombra bien colmada, / con este nunca lleno corazón, / honremos al Señor que hizo la Nada / y ha esculpido en la fe nuestra razón».

También tendremos que postular como significado más probable para el mar que aparece en CXXXVII-V («Profesión de fe») ese «mundo» especial del que hablamos. Para la elaboración del poema se ha utilizado la misma terminología y el mismo estilo contradictorio y paradójico de Unamuno. Nos encontramos en el momento preciso en el que más estrechas eran las relaciones entre ambos poetas. Y sin embargo, a pesar de las apariencias, su contenido no coincide totalmente con las ideas del rector de Salamanca. Sintetizando mucho lo que aparece en la filosofía de Unamuno es lo siguiente: Dios es la conciencia del universo. A conciencia se llega por el dolor: por el físico, a conciencia del cuerpo; por el espiritual, a conciencia del alma. Primero hay 
conciencia del alma individual, al descubrirse la limitación personal y la finitud; luego, por sobreabundancia de dolor, del alma del Todo, que también es sufrimiento. Ese Todo es materia y espíritu, pero el espíritu, la conciencia, está aprisionado en la materia, y en el devenir del mundo se va liberando progresivamente. El hombre busca a Dios por su afán de personalizarlo todo, para poder hablar con Él cara a cara y exigirle explicaciones; es en realidad una creación de nuestra voluntad; creer en Dios es querer creer en Dios.

Si estuviéramos obligados a explicar el poema en esa clave unamunesca, tendríamos que comenzar suponiendo que con el mar Machado se está refiriendo al Universo, y con Dios, a la conciencia del Universo; un Dios que no es el Universo mismo sino que está en él. Pero ya al final de la primera parte del poema aparece una afirmación que contradice esa línea interpretativa: la conciencia «se despierta o se adormece». Para Unamuno el desarrollo de la conciencia es progresivo, y no existe adormecimiento de ningún tipo. Y al comenzar la segunda parte, esa posibilidad de explicación se desvanece por completo: «Creó la mar». Si aceptamos que el mar es el Universo y que la conciencia lo crea, estaríamos entonces ante un idealismo exacerbado, algo inimaginable en estos momentos, ni en Machado ni en Unamuno. La expresión «Creó la mar» sería aceptable para aquel que cree en un Dios personalista situado fuera del Universo, pero una interpretación de ese tipo había quedado anulada desde un principio en el verso «Dios no es el mar, está en el mar.»

La cuestión se complica si dirigimos la mirada hacia el proverbio siguiente: «Por todas partes te busco / sin encontrarte jamás, / y en todas partes te encuentro / sólo por irte a buscar. (S. XXIV [3]). Hemos llegado ya en estos momentos al colmo de lo paradójico: un dios que cuando se busca, no se encuentra; y que se encuentra siempre cuando se busca. Pero en estos casos difíciles Machado suele dejarnos alguna pista o alguna señal que puede servirnos a nosotros, sus lectores, para encontrar el camino correcto. CXXXVIIV («Dios no es el mar, está en el mar») y CXXXVII-VI («El Dios que todos llevamos») son dos de las ocho «Parábolas» que aparecen en Campos de Castilla. Las anteriores: I («Era un niño que soñaba»), II («Sobre la limpia arena, en el tartesio llano»), III («Érase de un marinero») y VI («Sabe esperar, aguarda a que la marea fluya»); y las posteriores: VII («Dice la razón: busquemos») y VIII («Cabeza meditadora») presentan como asunto central el conocimiento humano y sus dificultades para alcanzar una verdad satisfactoria. Resultaría extraño que el Dios del que se habla en estas dos parábolas no tuviera relación con este problema, que es el más importante para Machado en estos momentos.

En el verso final de la séptima se nos dice que el que llevamos, el que hacemos y el que buscamos son tres formas del único Dios «verdadero», y precisamente esa palabra, «verdadero», es la que debemos retener. Un Dios verdadero es un Dios que tiene que ver con la verdad, y de la verdad trata 
precisamente la parábola que sigue a esta, sin que en ella se utilice ahora la palabra Dios, que es la que provoca las confusiones:

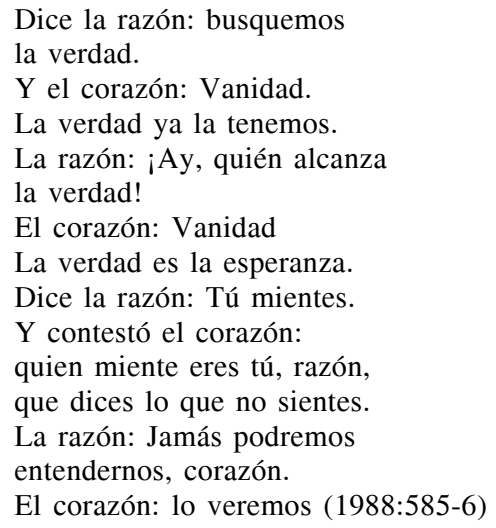

Si partimos para la interpretación de estos poemas de la presuposición de que el mar es el «mundo» de la existencia heideggeriano y de que con Dios se refiere Machado a la verdad, es decir, a la conciencia verdadera de lo que es el existir humano, podremos luchar contra las dificultades que presentan. «Profesión de fe» comienza con este verso:

Dios no es el mar, está en el mar

El «mundo» (el mar), el plexo de relaciones significativas en que el hombre se halla inmerso desde siempre y que es él siempre, no es, evidentemente, la verdad (Dios). Pero la verdad está en él («está en el mar»); camuflada pero ahí, en el «ahí» del «ser ahí», que ha abierto ese mundo y que «es» de modo inmediato «mundo».

en el mar se despierta o se adormece.

La conciencia verdadera de su existir, la verdad, Dios, en ese «mundo» (mar) se despierta o se adormece: en el «mundo» la llamada de la conciencia en la angustia se deja oír, pero también se acalla de modo habitual.

Creó la mar, y nace

de la mar cual la nube y la tormenta.

Con la expresión «Creó la mar» se dice que la verdad, el ser (Dios) da el ser al existir humano, lo «hace». Pero en el hombre, en su «mundo», se produce una ocultación de esa verdad. Dios, el ser, la verdad crea el «mundo» (mar) del «ser ahí»; y precisamente de ese «mundo» engañoso del «ser ahí» es de donde únicamente puede surgir la verdad. 
Yo he de hacerte, mi Dios, cual tú me hiciste.

El deber de Machado, como el de todo hombre es buscar la verdad (Dios), hacerla, pero teniendo siempre en cuenta que no le pertenece, que la verdad (Dios) le ha sido dada ya de modo previo, que él ha sido hecho por la verdad, que busca algo que ya tenía de modo previo pero se le ha ocultado.

Que el puro río

de caridad que fluye eternamente,

fluya en mi corazón.

La palabra «caridad» tiene en el poema el mismo sentido que en Unamuno tiene «liberación», aunque con un matiz distinto. Dice Unamuno: «Es, pues, la caridad el impulso a libertarse y a libertar a todos mis prójimos del dolor y a libertar a Dios que nos abarca a todos» (1980: 185). Uno de los dolores más grandes del hombre, si no el más, para Machado, es la ceguera en que vive. Y Dios está relacionado en su poesía con la verdad. El mandamiento más claro que Jesús (Dios) dio a los hombres fue el de estar alerta: «Todas tus palabras fueron / una palabra: velad» (CXXXVI-XXXIV).

Ese mar, es decir, la existencia humana, es un ámbito lleno de dificultades para el conocimiento. Con él, con el mar, tenía que mantener una de sus dos luchas el hombre que quería conocer la verdad en el poema CXXXVIXXVIII: «Todo hombre tiene dos / batallas que pelear: / en sueños lucha con Dios; / y despierto, con el mar». La razón humana nunca llegará hasta la verdad del existir humano porque la naturaleza estática de la lógica conceptual no puede dar cuenta de esa realidad en continuo cambio. El conocimiento que se alcanza a través de esa vía racional es un sueño. Y tiene siempre enfrente, como algo presente pero inalcanzable, la verdad, Dios. Es decir: el hombre tiene por naturaleza un intuitivo, y por lo tanto confuso, conocimiento de la verdad sobre su ser; y todas las «verdades» falsas que la razón concibe sobre ese ser chocan siempre con la verdad intuida. El hombre, pues, como dice el proverbio, en sueños, lucha con Dios, se enfrenta con la verdad. Pero, por otra parte, el hombre nunca se encuentra situado firmemente en la verdad intuida, porque de forma inmediata se extiende sobre ella el velo de sombras de las «verdades» racionales constituidas ya de antemano por la comunidad a la que pertenece. Cuando el hombre está «despierto», es decir, cuando ha intuido la verdad, la ve de inmediato falseada por la comprensión previa que tiene sobre las cosas. Despierto, tiene enfrente, como enemigo, el mar, la existencia humana en cuanto «mundo». Despierto, pues, como dice el proverbio, con lo que lucha el hombre es con el mar, con su propio existir, que es el que le oculta la verdad. Ésas serán siempre las dos batallas inevitables.

Si no estableciéramos previamente esa identificación Dios-verdad no podríamos explicar tampoco el sentido del poema S. XXIV [3] («Por todas par- 
tes te busco»), otro de los más paradójicos y más crípticos de Machado: «Por todas partes te busco / sin encontrarte jamás, / y en todas partes te encuentro / sólo por irte a buscar». No hay ninguna verdad (Dios) estable, fija, que se pueda encontrar y guardar. La verdad es el estar lanzado del existir humano, algo inestable, inasible, un abismo, un ir haciéndose continuamente. A esa verdad le conviene un término activo, dinámico, como «buscar»; no uno fijo, definitivo, como «encontrar». No se puede acceder de ninguna forma a una verdad como la de la existencia si no es con un procedimiento que tenga su naturaleza. A una verdad inasible como ésa sólo le conviene una filosofía de «búsqueda». Heidegger, por ejemplo, como dice Hugo Múgica, «es un pensador de caminos, no de llegada» (1995: 11). La filosofía de Heidegger no es un sistema estable de verdades fijas sino un camino, que busca la verdad sin esperanza de «encontrarla» jamás. Como dice Múgica, «toda su obra está atravesada por el signo del camino. Imagen que nos señala hacia un andar, una búsqueda y hasta un errar, pero nunca hacia una llegada. Jamás hacia una oclusión, una oclusión final: una sistematización» (1995: 22). Machado es, del mismo modo, un poeta que busca. Con sus símbolos va abriendo caminos para dar expresión a sus intuiciones de hombre, de un hombre que ha intuido desde un principio lo más importante: que no hay camino, que «se hace camino al andar».

\section{EL MAR, SÍMBOLO DEL EXISTIR HUMANO EN CUANTO «OLVIDO»}

Hay tres poemas en la última etapa de la obra de Machado en los que la palabra mar se relaciona con el olvido. Nada hay de extraño, y en nada contradice la suposición de la que hemos partido, la de que el mar simboliza la existencia humana. La esencia del hombre es la existencia. El existir es el ámbito del ser, de la verdad; no hay otro. La existencia es proyección, posibilidad, y una de sus posibilidades es la del olvido. La existencia puede «ser» olvido: olvido de la muerte en la existencia inauténtica, olvido del ser en el pensar metafísico. No se trata de una negligencia ni de un error que el hombre pueda subsanar: el olvido pertenece al ser, «es» también el ser. Y es únicamente desde el olvido desde donde se puede intuir (no re-construir) la verdad, una verdad que nunca se hará presente, que nunca será un presente estable, porque la verdad es el ser y el ser es des-ocultamiento. El hombre es olvido, y ese olvido suyo originario es la condición de posibilidad — lo que da la posibilidad — de cualquier otro olvido concreto posterior. No es sólo el olvido una forma de muerte; «la muerte, el silencio y el olvido» (CLXVII-XV) son formas de lo oculto del ser, la nada, aquello que nunca se hace presente para el hombre pero que está siempre ahí, sosteniendo la presencia, y es únicamente en ella donde se muestra, pero permaneciendo oculto. Como no se hace presente, para el pensar racionalista «no es» o es sólo lo contrario de lo presente, y le da un «ser ante los ojos», tam- 
bién presente: recuerdo-olvido. Pero el hombre no tiene unos recuerdos objetivos y fidedignos de los hechos del pasado y luego por un deterioro de la memoria los va olvidando; en ese caso lo primero sería la presencia y lo segundo la ocultación. Por el contrario, el hombre «crea», no recupera, los recuerdos del pasado. ¿Desde dónde? Desde los cimientos abismales sobre los que el recuerdo se levanta, desde el olvido. Y es ahí, en esos recuerdos «creados», donde el olvido únicamente se puede mostrar. El olvido, pues, «es» nada; solo se puede «ver» en el recuerdo; no tiene presencia; es lo que permanece oculto en la presencia del recuerdo, no sólo formando parte de él sino cobijándolo, sosteniéndolo.

En el poema CLXXIV-VIII ( «Abre el rosal de la carroña horrible / su olvido en flor [...]»), de «Otras canciones a Guiomar», hace aparece Machado un rosal de un estercolero, una mariposa de una tumba y un trigal de un paisaje espeluznante. Siempre algo pavoroso sosteniendo la presencia, como la nada -es decir, el «no ser», el ser sin fundamento de la existencia, el abismo- que «sostiene» la vida humana. La presencia pertenece a la ausencia, el recuerdo al olvido; es desde el olvido desde donde se crea el recuerdo. El poema termina así: «se ha abierto un abanico de milagros / —el ángel del poema lo ha querido_ — en la mano creadora del olvido...».

En el número III de esas mismas canciones se refiere Machado a la reconstrucción creadora de la amada a partir del olvido previo, un paso necesario en el proceso de enamoramiento: «Escribiré en tu abanico: / te quiero para olvidarte, / para quererte te olvido».

Es precisamente en el olvido en donde Abel Martín tiene que hundir su sueño de poeta, si quiere recuperar, recreándolo, el pasado, una de las funciones poéticas fundamentales: «Hoy, como un día, en la ancha mar violeta / hunde el sueño su pétrea escalinata, / y hace camino la infantil goleta, / y le salta el delfín de bronce y plata» (CLXIX).

Olvido y muerte tienen algo fundamental en común: son dos formas de lo oculto de la des-ocultación. Por eso, en uno de los poemas más bellos de Machado, el CLXIV-III, en el mismo símbolo del mar ambos significados se confunden. No tendría ningún sentido separarlos. Se alude otra vez al «estar lanzado» de la existencia, hecho de esperanza y miedo: «Con el incendio de un amor, prendido / al turbio sueño de esperanza y miedo, / yo voy hacia la mar, hacia el olvido, / - y no como a la noche ese roquedo, / al girar del planeta ensombrecido-. / No me llaméis, porque tornar no puedo».

Las rachas del viento de marzo, en su retiro valenciano, le recuerdan otras rachas del pasado, ya recluidas en los «desvanes» «del tiempo», caminando inexorablemente «hacia la mar», hacia el olvido: «Estas rachas de marzo, en los desvanes, / —hacia la mar- del tiempo; [...]».

Y llegamos así al final de nuestra indagación. El ser, para Heidegger, es el existir humano, proyectado sobre sus posibilidades, a las que llamó «existenciarios». El existir humano en cuanto proyección es de modo inmediato muerte 
física, muerte espiritual, «mundo», «estar lanzado» y olvido, los cinco valores que hemos delimitado para el símbolo del mar en Antonio Machado.

Pero, ¿y el mar que aparece en la «Glosa» a Manrique? De la sorpresa que nos produjo su lectura partimos al iniciar este artículo. Para su interpretación consideramos necesario, antes de nada, desentrañar el significado que la palabra mar ocultaba. Una vez descubierto, se hace ya posible una lectura coherente del poema

Tras el dulce gozo inconsciente del «vivir», está el falseamiento del «pasar», es decir, la concepción inauténtica del tiempo íntimo y el temor racional a la muerte, que no es lo mismo que estar situado en el estado de angustia en el que la muerte se muestra. Lo que se produce entonces es un «huir» vergonzoso hacia el «mar», hacia el estado de interpretado en la cotidianeidad. El «pavor del morir», el estado especial de la angustia en el que se siente la muerte, es una puerta, la única, para escapar del olvido y adentrarse en la verdad. «Tras» la angustia, está, en efecto, el «placer de llegar». Pero el «volver» es inevitable. Y a donde se vuelve es precisamente al mar, de donde se había partido. No se trata de que algunos hombres, por negligencia, se dejen llevar hacia el estado de caída, y que otros, como el poeta, hayan logrado salir de una vez para siempre. En ese caso se estaría diciendo que la verdad es un «objeto» a disposición del hombre y que, de ese modo, pertenece al hombre, que el ser pertenece al hombre. Pero en realidad nadie puede jactarse de haber alcanzado la verdad y de mantenerse siempre en ella. El hombre es un estar proyectado sobre las posibilidades inmediatas que se le presentan olvidando la más propia de todas, su propia muerte. El «mundo» que es él mismo, su «mundo, el que le ha correspondido históricamente, interpreta y falsea de modo inmediato su tiempo, su muerte y la nada. En ese sentido se puede decir que, más que el ser pertenezca al hombre, es el hombre el que pertenece al ser. Pero, en ese estado de interpretado, el hombre es el lugar, el único, en el que los entes y el ser, de los entes y de él mismo como ente, se muestran de modo luminoso. Y es entonces cuando el ser puede ser dicho. Desde el silencio, es decir, desde el ensordecimiento de las habladurías de la cotidianeidad, el poeta escucha; distingue las «voces» de los «ecos», esas voces que le llegan desde lo más profundo de la lengua, desde «la casa del ser» (2000: 11), en la afortunada expresión de Heidegger. La voz, por ejemplo, de Manrique, en la que resuena la verdad, a pesar de él $\operatorname{mismo}^{8}$, a pesar de la interpretación que su «mundo» inmediatamente realiza de ella. Donde Manrique dice «Nuestras vidas son los ríos / que van a dar a la mar, / que es el morir» se dice, por

${ }^{8}$ Años antes de que Heidegger centrara el problema del ser en la lengua, decía Machado las siguientes palabras, puestas en boca de su heterónimo Juan de Mairena, que a su vez cita a su maestro Abel Martín: «Las obras poéticas realmente bellas, decía mi maestro - habla Mairena a sus discípulos-, rara vez tienen un solo autor. Dicho de otro modo: son obras que se hacen solas, a través de los siglos y de los poetas, a veces a pesar de los poetas mismos, aunque siempre, naturalmente, en ellos» (Machado, 1989: 2015). 
supuesto, que la vida del hombre es un continuo fluir hacia la muerte, pero también que la vida humana consiste en un incesante e inevitable huida hacia otra forma de muerte. Y su voz seguirá hablándole al hombre a través de los siglos sin agotar nunca su sentido. Porque es posible, como pensaba Heidegger, que no sea el hombre el que habla una lengua, tomada como un instrumento situado fuera de él que se refiere a «cosas», sino que es la lengua la que habla a través del hombre y es en ella, sólo en ella, donde la «cosa» llega a ser. No en la lengua instrumental de la cotidianeidad sino en la lengua de la poesía. El poeta es el hombre que pone el ser en la palabra. En ese sentido, se puede decir que también el ser pertenece al hombre, en cuanto el ser, la verdad, necesita del hombre para poderse manifestar.

\section{BIBLIOGRAFÍA CITADA}

Ángeles, José (1966). «El mar en la poesía de Antonio Machado», Hispanic Review. XXXIV, pp. $27-48$.

Cirlot, J-E (1994). Diccionario de símbolos. (10ª ed.). Barcelona: Labor.

Eliade, Mircea (1979). Historia de las creencias y de las ideas religiosas II: De Gaudama Buda al triunfo del cristianismo. Madrid: Ediciones de la Cristiandad.

García Castro, José María (2012). La filosofía poética de Antonio Machado. Tesis doctoral. Pamplona: Universidad de Navarra.

Gener Cuadrado, Eduardo (1966). El mar en la poesía de Antonio Machado. Madrid: Editora Nacional.

Heidegger, Martin (1989). El ser y el tiempo. José Gaos (trad.). 2a ed. México: Fondo de Cultura Económica.

Heidegger, Martin (2000). Carta sobre el humanismo. Madrid: Alianza.

Lapesa, Rafael (1989). «Sobre algunos símbolos en la poesía de Antonio Machado», en Francisco López (ed.), En torno a Antonio Machado. Madrid: Júcar, p. 55-115.

Machado, Antonio (1984). Soledades. Galerías. Otros poemas. Geoffrey Ribbans (ed.). Madrid: Cátedra.

Machado, Antonio (1988). Poesía y Prosa. Macrì, Oreste (ed.). 4 t. Madrid: Espasa-Calpe y Fundación Antonio Machado.

Machado, Antonio (2001). Prosas dispersas (1893-1936). Jordi Doménech (ed.). Madrid: Páginas de Espuma.

Machado, Antonio (2007). Apuntes de Filosofía. Transcripción y edición del cuaderno manuscrito por Filomena Garrido Curiel. Granada: Universidad de Granada.

Merchán Juan (2004). Un canto de frontera. La lógica poética de Antonio Machado. Tesis doctoral. Almería: Universidad de Almería.

Merchán, Juan (2010). «La presencia de Nietzsche en Antonio Machado». Abel Martín. Revista de estudios sobre Antonio Machado, http://www.abelmartin.com, junio.

Múgica, Hugo (1995). La palabra inicial. La mitología del poeta en la obra de Heidegger. Madrid: Trotta.

Unamuno, Miguel (1980). Del sentimiento trágico de la vida. Madrid: Espasa-Calpe. 